\title{
Morbid Obesity and Obstructive Sleep Apnea: The Challenging Link
}

\author{
Thomas J. Ebert* and Jutta Novalija
}

Medical College of Wisconsin and VA Medical Center, Milwaukee, WI, USA

\begin{abstract}
Obstructive sleep apnea (OSA) is a common medical condition that is increasing in prevalence and is associated with substantial morbidity and a $40 \%$ eight-year mortality rate if left untreated. Morbidly obese patients have a greater incidence of co-morbid disease, including OSA. OSA is characterized by repeated upper airway obstruction and arousal during sleep, sympathetic activation, hypertension and daytime somnolence. In morbidly obese OSA patients undergoing surgical procedures, the perioperative period is more challenging than in non obese OSA patients. Their airway anatomy is often abnormal with excess pharyngeal tissue and tongue size making it difficult to ventilate thru a facemask and to establish tracheal intubation. Several suggestions for optimizing the anesthetic induction, emergence, and early recovery periods in these patients are offered. Most important are positioning of the patient (both during and post surgery), pre-oxygenation prior to intubation, proper dosing of anesthetic maintenance drugs to ideal body weight, alveolar recruitment maneuvers, full reversal of paralysis at the end of surgery, and careful drug titration in recovery to improve pulmonary mechanics. With proper preparation and precautions it is possible to avoid the significant high frequency of respiratory and cardiac complications observed in these patients and to avoid or better manage length of hospital stay, unplanned ICU admission and/or reintubation.
\end{abstract}

Keywords: Difficult airway, obstructive sleep apnea, position, oxygenation, denitrogenation.

\section{INTRODUCTION}

Worldwide, obesity in both children and adults continues to increase in most countries and to a greater extent in developed countries. Obesity is an epidemic with major health consequences. More than 60 million adults and 9 million children are obese or overweight [1]. Morbid obesity (MO) refers to patients with a BMI $>40 \mathrm{~kg} / \mathrm{m}^{2}$ or a BMI $\geq 35$ $\mathrm{kg} / \mathrm{m}^{2}$ with significant co-morbid conditions. MO is associated with an increased prevalence of disease, including hypertension, coronary heart disease, congestive heart failure, stroke, osteoarthritis, type II diabetes, insulin resistance, glucose intolerance, hypercholesterolemia, gallstones, cholecystitis, cholelithiasis, and obstructive sleep apnea (OSA). The frequency and severity of co-morbid conditions, including OSA, increase proportionally to the weight of the patient. The high prevalence of co-morbid conditions requires that the preoperative evaluation occurs early enough to determine that underlying pathology such as coronary artery disease, is stable and optimally managed. Similarly, pulmonary function, GE reflux, diabetes and glucose control should be evaluated and optimized (Table 1). Once pre-operative conditions are addressed, their impact on the anesthetic management should be determined in the process of developing the best perioperative management plan.

\section{AIRWAY STRUCTURAL CHALLENGES OF OSA AND MO}

For patients with obstructive sleep apnea, the perioperative period is known to be challenging from the time of

*Address correspondence to this author at the Medical College of Wisconsin and VA Medical Center, Milwaukee, WI, USA; Tel: 414-384-2000, ext. 42424;

Fax: 414-384-2939; E-mail: tjebert@mcw.edu initial airway management through postoperative care. Obesity is one of several key predictors of the presence of OSA [2,3]. Obesity is associated with fat deposition in the pharyngeal region, thereby narrowing the natural airway and adding to the prevalence and severity of OSA. Obesity also is correlated with tongue weight and the percent of fat in the posterior tongue [4]. Thus, obesity and OSA have a troubling, perhaps additive effect that leads to a greater severity of OSA and a higher frequency of difficult intubation. The reverse also is true. It has been shown that patients with difficult intubation have a higher incidence of OSA on polysomnography testing [5].

Aside from problems with redundant pharyngeal tissue and a large tongue affecting airway patency, abdominal obesity has mechanical effects on the upper airway (UA). Studies have demonstrated that the reduced lung volume associated with obesity contributes to poor UA function in OSA patients [6,7]. A decrease in lung volume potentially reduces the degree of caudal traction exerted on the UA, and promotes UA collapse. Support for this interaction can be found in a study where abdominal compression during sleep in OSA patients worsened UA collapse [8]. The effect of abdominal obesity on UA function may be most evident in the supine posture and during sleep, particularly at the wake-sleep transition when other compensatory mechanisms become diminished.

\section{DIFFICULT AIRWAY}

Not surprisingly, the presence of OSA is an independent risk factor for difficult mask ventilation after anesthetic induction $[9,10]$. During wakefulness, patients with OSA compensate for diminished airway anatomical features by increasing the cranio-cervical angulation that lifts the 
hyo-mandibular complex (tongue, soft tissues and mandible) away from the spine, thereby increasing the airway space [11]. This useful compensation is lost during anesthesia since most anesthetics diminish critical UA muscular tone, thereby promoting airway collapse [12-16].

Because of the strong association between obesity and OSA and because the majority of OSA patients are undiagnosed at the time of surgery, the anesthesia provider must be well prepared for difficulties with airway management. This means having help available and having several devices available to handle the difficult mask ventilation and difficult intubation. In 2002, Brodsky and colleagues identified two important correlates of difficult intubation: Mallampati $\geq 3$ and neck circumference $>40 \mathrm{~cm} \mathrm{[17].} \mathrm{Several} \mathrm{years} \mathrm{later,}$ the role of neck circumference for predicting problematic intubation was reaffirmed [18]. A neck circumference of $>43$ $\mathrm{cm}$ had a sensitivity of $92 \%$ and a specificity of $84 \%$ for predicting difficult intubation (Table 1). Historically, the intubation of the morbidly obese (MO) patient with OSA and a suspected difficult airway was most commonly managed with an awake, fiberoptic technique. However, recent studies have described a $96 \%$ success rate when using an alternate airway device called the intubating laryngeal mask airway (ILMA) in MO patients $[19,20]$. In one study, $100 \%$ of the MO patients were successfully ventilated through the LMA [21]. Whether these promising outcomes persist when using an ILMA in a MO patient with OSA is not known. Both the LMA CTrach ${ }^{\mathrm{TM}}$ and the Airtraq ${ }^{\mathrm{TM}}$ have been shown to be effective and potentially advantageous compared to standard laryngoscopy in the MO patient [21, 22].

\section{OPTIMIZING THE ANESTHETIC INDUCTION PERIOD}

Prior to induction, there are some maneuvers that will increase the likelihood of successful ventilation and intubation and will afford a longer period of apnea before the onset of significant oxygen desaturation. Proper positioning of the MO patient consists of supporting the patient behind the upper back and head to achieve the anatomical position where the head is above the horizontal plane of the upper chest and a horizontal plane between the sternal notch and the external auditory meatus is established (Table 1). This positioning not only improves pulmonary mechanics, but also improves the alignment from mouth to glottic opening. In patients with OSA, the sitting posture decreases the frequency of OSA compared to supine and the benefits gained from upright positioning are further enhanced in the MO patient [23]. This observation adds support for ramping or moving patients into a sitting position for preoxygenation and anesthetic induction. Awake, fiberoptic intubation and/or LMA placement after induction can be successfully performed in the seated position [24].

Preoxygenation is vitally important since the MO patient has a reduced functional residual capacity (FRC), and tidal volume often falls below the closing capacity of the small airways, leading to atelectasis, increased intrapulmonary shunting, and impaired oxygenation (Table 1). FRC is further reduced after induction of anesthesia when the weight of the chest wall compresses the thorax. Conventional techniques to denitrogenate the lungs, including at least three minutes of breathing $100 \%$ oxygen or five vital capacity breaths of $100 \%$ oxygen must be applied.
Because of the more rapid decline in oxygen saturation during apnea in the MO patient, strategies to improve the time to desaturation during apnea have been studied (Table 2).

- When 3 minutes of preoxygenation are provided while the patient is in the $25^{\circ}$ head-up tilt position, $\mathrm{PaO}_{2}$ is increased by $82 \mathrm{~mm} \mathrm{Hg}$, and the duration of apnea before desaturation to $92 \%$ occurred was increased nearly a minute compared to horizontal positioning [25].

- Many OSA patients use some form of continuous positive airway pressure (CPAP) at home to help with sleep architecture. The administration of oxygen via 10 $\mathrm{cm} \mathrm{H}_{2} \mathrm{O}$ of CPAP for five minutes to patients prior to induction of anesthesia, followed by $10 \mathrm{~cm} \mathrm{H}_{2} \mathrm{O}$ positive end-expiratory pressure (PEEP) via mask prior to intubation [26] is another technique to add up to one minute of additional time before apnea results in significant desaturation.

- Newer anesthesia machines allow the administration of pressure support and, when done with a tight fitting mask in a MO patient for three minutes, one might expect a delayed time to desaturation during apnea.

The primary goal to these maneuvers is gaining valuable time before critical desaturation occurs if intubation proves difficult.

After induction, two maneuvers might help with mask ventilation. The first is to bring the patient into a seated position (if not already there). For example, under propofol/ vecuronium anesthesia, moving the patient from the supine to the sitting position improved (enlarged) both retropalatal and retroglossal regions in anesthetized and paralyzed patients with OSA, indicating that the structural properties of the passive pharynx were improved [12]. Second, and perhaps a bit easier to implement, is to extend the neck, enhancing the "sniffing" position for improved pharyngeal airway patency in OSA patients [27]. Insertion of the LMA ProSeal $^{\mathrm{TM}}$ has been shown to be an effective temporary ventilation device before laryngoscopic-guided tracheal intubation in MO patients [28]. This and other supraglottic airway devices should be successful in the MO patient with OSA because they would open collapsed pharyngeal structures and displace a fattened tongue.

\section{EMERGENCE AND EARLY RECOVERY}

Alveolar recruitment maneuvers should be considered throughout surgery and just prior to emergence and extubation to lessen any atelectasis that has occurred during the surgical period (Table 1). One approach is to set tidal volume to $10 \mathrm{ml} / \mathrm{kg}$ ideal body weight at a rate of 8 breaths per minute and provide a 3 -step sequential increase in PEEP, beginning just prior to surgical incision, then at 30-60 min thereafter until the end of surgery. Specifically, one recruitment procedure would be applying PEEP for 3 to 4 breaths at each of 10,15 and $20 \mathrm{~cm} \mathrm{H}_{2} \mathrm{O}$ sequentially, but not to exceed a peak airway pressure of $50 \mathrm{~cm} \mathrm{H}_{2} \mathrm{O}$. Between maneuvers, PEEP is maintained at $10-12 \mathrm{~cm} \mathrm{H}_{2} \mathrm{O}$ for the entire operation [29]. Strict extubation criteria should be followed (Table 1). A train-of-four ratio of 0.9 or greater must be achieved and a 5 -second head lift performed. If extubation is not planned or criteria are not met, sufficient sedation should be provided to prevent "bucking" on the tube, thereby less- 
Table 1. Considerations for Safe Anesthesia in Obese Patients with OSA

\begin{tabular}{|c|c|c|}
\hline When & What & Anticipated Result \\
\hline \multirow[t]{3}{*}{ Pre-operatively } & Assess and optimize co-morbid conditions & Reduces incidence of adverse events/outcomes \\
\hline & Extra personnel available & Assistance for difficult airway management \\
\hline & Ramped or seated position & Improve FRC and likelihood of successful mask ventilation and intubation \\
\hline \multirow[t]{2}{*}{ Induction/Intubation } & Neck circumference $>43 \mathrm{~cm}$ & Predicts a more difficult intubation \\
\hline & Preoxygenation (See Table 2) & Denitrogenation of lungs, prolongs time to significant desaturation during apnea \\
\hline Maintenance/Emergence & Alveolar recruitment maneuvers & Lessens atelectasis, lessens intrapulmonary shunt \\
\hline Extubation & $\begin{array}{l}\text { Must meet strict criteria: Train-of-four of } 0.9 \text { or } \\
\text { greater; } 5 \text {-sec head lift }\end{array}$ & Full return of respiratory muscle function \\
\hline Early recovery & Multi-modal approach with non-opioid analgesics & Avoids unwanted depression of respiratory drive \\
\hline
\end{tabular}

Table 2. Preoxygenation Strategies

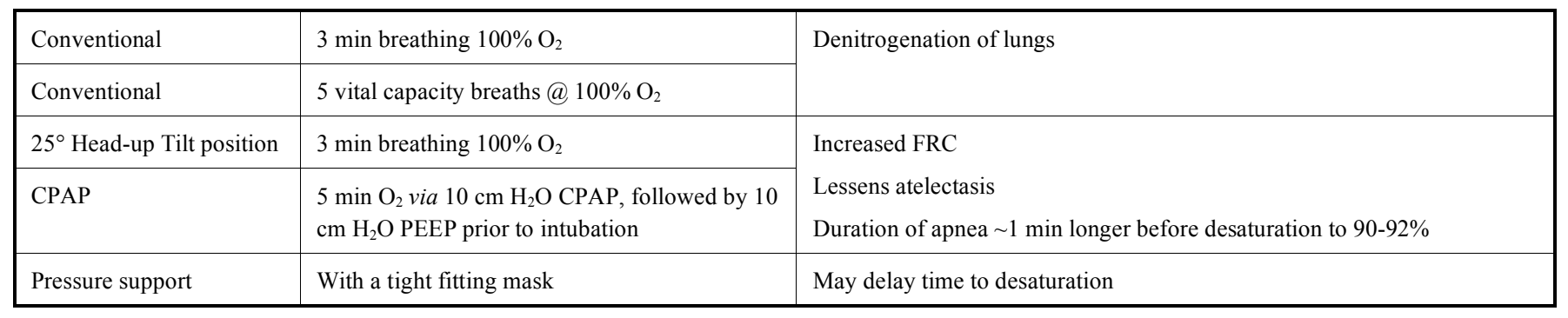

ening the likelihood of negative pressure pulmonary edema. During and/or after extubation, improved pulmonary mechanics can be achieved by a semi-upright position to reduce the effects of FRC on closing volumes, thereby improving oxygenation. The position also helps avoid airway collapse. An interesting study that might be relevant for the MO patient with OSA has described the effects of residual amounts of volatile anesthetics (0.1 MAC) on the hypoxic drive to ventilate [30]. Sevoflurane and desflurane preserved the response better than isoflurane, halothane, and enflurane. This might prove advantageous during the early PACU course.

An important goal in recovery from anesthesia is choosing a multi-modal approach with non-opioid analgesics to control post-operative pain (Table 1). Obese persons metabolize lipophilic drugs to a greater degree and for longer periods than non-obese controls. Increased body fat increases the volume distribution of sufentanil and slows its elimination. Actual body weight dosing of fentanyl overestimates dose requirements in obese patients [31]. The preferred approach is to dose opioids to ideal body weight and titrate as needed thereafter. Regional techniques may be preferred to manage post-operative pain to minimize opioids and their unwanted effects on respiratory drive. Anatomic challenges (obesity) should not limit the attempt to place a regional block. The benefits of success far outweigh the challenges and possible extra time needed. Ultrasound may help in identification of anatomical structures and confirmation of adequate spread of local anesthetics. Feld et al. reported an interesting approach to post-operative pain management after gastric bypass surgery [32]. A non-opioid regimen that in- cluded ketorolac, clonidine, lidocaine, ketamine, magnesium sulfide, and methylprednisolone provided pain relief comparable to an opioid, but with less sedation. We have had success with the sole use of the alpha $a_{2}$-agonist dexmedetomidine for pain management after major in-patient surgery [33]. Although dexmedetomidine is known to preserve respiratory drive, it also promotes a natural sleep-like state. If true, the risks of sleep and airway collapse in the OSA patient need to be considered.

\section{SUMMARY}

The close link between MO and the presence and severity of OSA presents certain challenges in these patients during the perioperative period. Evaluation of co-morbid conditions along with a careful assessment of airway risk helps in developing the anesthetic plan. Both patient positioning and pre-oxygenation must be optimized. Anesthetic maintenance should include drugs dosed to ideal body weight, alveolar recruitment maneuvers and a full reversal of paralysis at the end of the surgery. Upright positioning in recovery and careful drug titration are essential to improve pulmonary mechanics and to avoid respiratory depression.

\section{REFERENCES}

[1] Ogden CL, Carroll MD, McDowell MA, Flegal KM. Obesity Among Adults in the United States - No Statistically Significant Change Since 2003-2004. National Center for Health Statistics 2007.

[2] Dixon JB, Schachter LM, O'Brien PE. Predicting sleep apnea and excessive day sleepiness in the severely obese: indicators for polysomnography. Chest 2003; 123: 1134-41. 
[3] Young T, Paulta M, Dempsey J, Skatrud J, Weber S, Badr S. The occurrence of sleep-disordered breathing among middle-aged adults. N Engl J Med 1993; 328: 1230-5.

[4] Nashi N, Kang S, Barkdull GC, Lucas J, Davidson TM. Lingual fat at autopsy. Laryngoscope 2007; 117: 1467-73.

[5] Hiremath AS, Hillman DR, James AL, Noffsinger WJ, Platt PR, Singer SL. Relationship between difficult tracheal intubation and obstructive sleep apnoea. Br J Anaesth 1998; 80: 606-11.

[6] Heinzer RC, Stanchina ML, Malhotra A, et al. Effect of increased lung volume on sleep disordered breathing in patients with sleep apnoea. Thorax 2006; 61: 435-9.

[7] Stanchina ML, Malhotra A, Fogel RB, et al. The influence of lung volume on pharyngeal mechanics, collapsibility, and genioglossus muscle activation during sleep. Sleep 2003; 26: 851-6.

[8] Stadler DL, McEvoy RD, Sprecher KE, et al. Abdominal compression increases upper airway collapsibility during sleep in obese male obstructive sleep apnea patients. Sleep 2009; 32: 1579-87.

[9] Langeron O, Masso E, Huraux C, et al. Prediction of difficult mask ventilation. Anesthesiology 2000; 92: 1229-35.

[10] Kheterpal S, Tremper KK, Englesbe MJ, et al. Predictors of postoperative acute renal failure after noncardiac surgery in patients with previously normal renal function. Anesthesiology 2007; 107: 892-902.

[11] Solow B, Ovesen J, Nielsen PW, Wildschiodtz G, Tallgren A. Head posture in obstructive sleep apnoea. Eur J Orthod 1993; 15: 107-14.

[12] Tagaito Y, Isono S, Tanaka A, Ishikawa T, Nishino T. Sitting posture decreases collapsibility of the passive pharynx in anesthetized paralyzed patients with obstructive sleep apnea. Anesthesiology 2010; 113: 812-8

[13] Eastwood PR, Platt PR, Shepherd K, Maddison K, Hillman DR. Collapsibility of the upper airway at different concentrations of propofol anesthesia. Anesthesiology 2005; 103: 470-7.

[14] Eastwood PR, Szollosi I, Platt PR, Hillman DR. Collapsibility of the upper airway during anesthesia with isoflurane. Anesthesiology 2002; 97: 786-93

[15] Norton JR, Ward DS, Karan S, et al. Differences between midazolam and propofol sedation on upper airway collapsibility using dynamic negative airway pressure. Anesthesiology 2006; 104: 1155-64.

[16] Eikermann M, Fassbender P, Zaremba S, et al. Pentobarbital dosedependently increases respiratory genioglossus muscle activity while impairing diaphragmatic function in anesthetized rats. Anesthesiology 2009; 110: 1327-34.

[17] Brodsky JB, Lemmens HJM, Brock-Utne JG, Vierra M, Saidman LJ. Morbid obesity and tracheal intubation. Anesth Analg 2002; 94: 732-6.

[18] Gonzalez H, Minville V, Delanoue K, Mazerolles M, Concina D, Fourcade $\mathrm{O}$. The importance of increased neck circumference to intubation difficulties in obese patients. Anesth Analg 2008; 106: 1132,6 , table of contents.
[19] Frappier J, Guenoun T, Journois D, et al. Airway management using the intubating laryngeal mask airway for the morbidly obese patient. Anesth Analg 2003; 96: 1510-5.

[20] Combes X, Sauvat S, Leroux B, et al. Intubating laryngeal mask airway in morbidly obese and lean patients. Anesthesiology 2005; 102: 1106-9.

[21] Dhonneur G, Ndoko SK, Yavchitz A, et al. Tracheal intubation of morbidly obese patients: LMA CTrach vs direct laryngoscopy. Br J Anaesth 2006; 97: 742-5.

[22] Ndoko SK, Amathieu R, Tual L, et al. Tracheal intubation of morbidly obese patients: a randomized trial comparing performance of Macintosh and Airtraq laryngoscopes. Br J Anaesth 2008; 100: 263-8.

[23] McEvoy RD, Sharp DJ, Thornton AT. The effects of posture on obstructive sleep apnea. Am Rev Respir Dis 1986; 133: 662-6.

[24] Ovassapian A, Tuncbilek M, Weitzel EK, Joshi CW. Airway management in adult patients with deep neck infections: A case series and review of the literature. Anesth Analg 2005; 100: 585-9.

[25] Dixon BJ, Dixon JB, Carden JR, et al. Preoxygenation is more effective in the $25^{\circ}$ head-up position than in the supine position in severely obese patients. Anesthesiology 2005; 102: 1110-5.

[26] Gander S, Frascarolo P, Suter M, Spahn DR, Magnusson L. Positive end-expiratory pressure during induction of general anesthesia increases duration of nonhypoxic apnea in morbidly obese patients. Anesth Analg 2005; 100: 580-4.

[27] Isono S, Tanaka A, Ishikawa T, Tagaito Y, Nishino T. Sniffing position improves pharyngeal airway patency in anesthetized patients with obstructive sleep apnea. Anesthesiology 2005; 103: 489-94.

[28] Keller C, Brimacombe J, Kleinsasser A, Brimacombe L. The laryngeal mask airway ProSealTM as a temporary ventilatory device in grossly and morbidly obese patients before laryngoscopeguided tracheal intubation. Anesth Analg 2002; 94: 737-40.

[29] Weingarten TN, Whalen FX, Warner DO, et al. Comparison of two ventilatory strategies in elderly patients undergoing major abdominal surgery. Br J Anaesth 2010; 104: 16-22.

[30] van den Elsen M, Sarton E, Teppema L, Berkenbosch A, Dahan A. Influence of 0.1 minimum alveolar concentration of sevoflurane, desflurane and isoflurane on dynamic ventilatory response to hypercapnia in humans. Br J Anaesth 1998; 80: 174-82.

[31] Shibutani K, Inchiosa MA, Sawada K, Bairamian M. Accuracy of pharmacokinetic models for predicting plasma fentanyl concentrations in lean and obese surgical patients. Anesthesiology 2004; 101: 603-13.

[32] Feld JM, Laurito CE, Beckerman M, Vincent J, Hoffman WE Non-opioid analgesia improves pain relief and decreases sedation after gastric bypass surgery. Can J Anaesth 2003; 50: 336-41.

[33] Arain SR, Ruehlow RM, Uhrich TD, Ebert TJ. Efficacy of dexmedetomidine versus morphine for post-operative analgesia following major inpatient surgery. Anesth Analg 2004; 98: 153-8. 